\title{
An Improved Car-Following Model Accounting for Impact of Strong Wind
}

\author{
Dawei Liu, Zhongke Shi, and Wenhuan Ai \\ College of Automation, Northwestern Polytechnical University, Xi'an, Shaanxi 710072, China \\ Correspondence should be addressed to Zhongke Shi; shizknwpu@163.com
}

Received 17 March 2017; Revised 18 June 2017; Accepted 13 July 2017; Published 25 October 2017

Academic Editor: Renming Yang

Copyright ( 2017 Dawei Liu et al. This is an open access article distributed under the Creative Commons Attribution License, which permits unrestricted use, distribution, and reproduction in any medium, provided the original work is properly cited.

\begin{abstract}
In order to investigate the effect of strong wind on dynamic characteristic of traffic flow, an improved car-following model based on the full velocity difference model is developed in this paper. Wind force is introduced as the influence factor of car-following behavior. Among three components of wind force, lift force and side force are taken into account. The linear stability analysis is carried out and the stability condition of the newly developed model is derived. Numerical analysis is made to explore the effect of strong wind on spatial-time evolution of a small perturbation. The results show that the strong wind can significantly affect the stability of traffic flow. Driving safety in strong wind is also studied by comparing the lateral force under different wind speeds with the side friction of vehicles. Finally, the fuel consumption of vehicle in strong wind condition is explored and the results show that the fuel consumption decreased with the increase of wind speed.
\end{abstract}

\section{Introduction}

As an important part of modern traffic flow theory, carfollowing theory describes how the vehicle follows the vehicle ahead. The principle of the car-following model is that the acceleration or deceleration of the vehicle depends entirely on the driver's response to the stimuli from the surrounding vehicles. Because the research of car-following model is of great significance to traffic management and traffic safety analysis, it has been proposed as early as 1950s. Pipes [1] presented the first car-following model in 1953. Subsequently, researchers have developed some classic models [25]. Newell [2] derived a car-following model with time delay which is important to exploring the evolution of traffic jam. Bando et al. [3] proposed an optimal velocity model (OVM) to reveal the complex dynamic characteristics of traffic flow. To solve the problem of excessively high acceleration and unrealistic deceleration in OVM, generalized force model (GFM) has been developed by Helbing and Tilch [4]. Based on the GFM, Jiang et al. [5] developed a car-following model called full velocity difference model (FVDM). In recent years, car-following theory has been rapidly developed and many models have been proposed to describe traffic phenomena and driving behavior. These new models focused on many different factors that influence car-following behavior, like the effects of time delay [6-9], multiple-vehicle in front [10-13], lane changing [14-19], the heavy vehicles [20-23], driver's behaviors [24-33], and some other factors in the literatures [34-44]. Nagatani [12] found that the car interaction before the next car ahead can stabilize the traffic flow. Tang et al. [14] presented a car-following model on two lanes by considering the lateral effects in traffic. They believed that vehicle drivers always worry about the lane changing actions from neighbor lane and the consideration of lateral effects could stabilize the traffic flows on both lanes. Peng and Cheng [27] developed an extended model based on FVDM through substituting an anticipation optimal velocity with optimal velocity and discussed the impact of driver's forecast on traffic flow stability. Liu et al. [31] believed that short-term driving memory can influence the driver's anticipation behavior. Yu and Shi [33] put forward an improved car-following model in the connected cruise control strategy to investigate the effects of multiple preceding cars' velocity changes with memory on each car's speed and acceleration, the relative distance, fuel consumption, and $\mathrm{CO}, \mathrm{HC}$, and NOX emissions.

However, in these car-following models mentioned above, little effort has been made to study the effect of inclement weather on driving behavior. Inclement weather, 
especially strong winds, has important influence on traffic safety, and traffic accidents caused by strong winds often appear in the news. A British study showed that up to 318 accidents were caused by strong winds from January 2002 to June 2007. In the case of driving in strong wind, drivers will always consider the impact of it to avoid traffic accident, so it is necessary to study the effect of strong wind on the driving behavior. Many researches have been done to investigate the effect of wind. Kwon et al. [45] explored that wind force acting on the vehicle has great effect on occurrence of traffic accidents. Baker [46, 47] found that overturning accidents, sideslip accidents, and rotation accidents are three most common types of traffic accident which can be induced by wind. In addition, they further presented the mathematical model of wind-induced accident risk. Xu et al. [48] explored the vehicle stability driving model with considering crosswind and obtained the limit minimum radii of horizontal curve in the conditions of different wind speeds.

However, the above works on strong wind only focus on studying the impact of strong wind from the perspective of traffic safety. To investigate the effect of strong wind on the micro driving behavior of vehicle, we develop an extended car-following model in this paper. This paper is organized as follows. In Section 2, a new improved car-following model based on FVDM is proposed by taking into account the effect of strong wind. In Section 3, linear stability analysis is carried out and the stability condition of this model is obtained. In Section 4, a series of numerical simulations is proposed to confirm the theoretical results. Conclusions are given in Section 5 .

\section{Model}

Among the existing car-following models, the full velocity difference model (FVDM) proposed by Jiang et al. [5] is the most effective one, which can describe many car-following behaviors appearing in the real traffic. FVDM can be written as follows:

$$
\frac{d x_{n}^{2}(t)}{d t^{2}}=a\left[V(\Delta x)-v_{n}\right]+\lambda \Delta v_{n}
$$

where $x_{n}(t)$ is the position of the $n t h$ vehicle at time $t ; \Delta x=$ $x_{n+1}-x_{n}$ and $\Delta v_{n}=v_{n+1}-v_{n}$ are the headway and the velocity difference between successive vehicles, respectively. $V(\Delta x)$ is the $n$th vehicle's optimal velocity which is a function of headway and can be expressed as follows:

$$
V(\Delta x)=V_{1}+V_{2} \tanh \left(C_{1}\left(\Delta x_{n}-L c\right)-C_{2}\right),
$$

Where $V_{1}, V_{2}, C_{1}, C_{2}$ are parameters, respectively, and their values are the same as those in [5].

In the case of driving in the weather of strong wind, driving behavior always has been affected not only by the vehicle ahead, but also in a large degree by the wind force on vehicle. Driver in the vehicle behind will keep following with the leading vehicle. At the same time, he will consider the impact from strong wind especially lateral wind which can make the vehicle's control harder. When the wind force is great enough to make the driver feel uncomfortable to control the vehicle, adjusting the driving speed will be done by the driver to reduce the impact of wind.

According to automobile aerodynamics [49], the wind force on the stationary vehicle can be decomposed into drag force $\left(F_{X}\right)$, lift force $\left(F_{Z}\right)$, and the side force $\left(F_{Y}\right)$, which can be formulated as follows:

$$
\begin{gathered}
F_{X}=0.5 C_{D} S \rho v_{w}^{2}, \\
F_{Y}=0.5 C_{L} S \rho v_{w}^{2}, \\
F_{Z}=0.5 C_{Z} S \rho v_{w}^{2},
\end{gathered}
$$

where $C_{D}, C_{L}, C_{Z}$ are, respectively, drag coefficient, lift coefficient, and side force coefficient. $\rho$ and $v_{w}$ are, respectively, air density and velocity of the wind. $S$ represents windward area of vehicle. Windward area is related to the angle between the wind direction and the vehicle.

In this paper, we investigate the wind force on the running vehicle. In addition, we consider that there always exists an angle between the wind direction and the driving direction in real traffic. According to the above reasons, we rewrite (3) as follows:

$$
\begin{aligned}
& F_{X}=0.5 C_{D} B H \rho\left(v_{w} \cos (\theta)\right)^{2}, \\
& F_{Y}=0.5 C_{Z} L c H \rho\left(v_{w} \sin (\theta)\right)^{2} \\
& F_{Z}=0.5 C_{L} B L c \rho v_{r}^{2},
\end{aligned}
$$

where $v_{r}=\sqrt{v_{n}^{2}+v_{w}^{2}-2 v_{n} v_{w} \cos (\theta)}$ represents relative velocity of the wind and the vehicle. $\theta$ is the angle between the wind direction and the driving direction. $L c, B$, and $H$ are, respectively, length, width, and height of the vehicle.

Among three force components of wind force, side force $\left(F_{Y}\right)$ has the greatest influence on the vehicle's driving stability [50]. Furthermore, lift force $\left(F_{Z}\right)$ is also taken into account since it will gradually become strong with the increasing relative velocity of wind to the vehicle; as a result the actual weight of vehicle is reduced. That is why driver has the feeling of floating in the case of driving in a high speed. The greater lift force will also affect the vehicle's steering stability. Based on above consideration, we take side wind force and lift force into account and propose the car-following model under strong wind, which can be expressed as

$$
\frac{d x_{n}^{2}}{d t^{2}}=a\left[\overline{V(\Delta x)}-v_{n}\right]+\lambda \Delta v_{n},
$$

where $\overline{V(\Delta x)}$ is modified optimal velocity with the consideration of the wind effect. For simplicity, we define $\overline{V(\Delta x)}$ as follows:

$$
\overline{V(\Delta x)}=V(\Delta x)+\widetilde{v},
$$

where $\widetilde{v}$ is adjustable speed of optimal velocity under the influence of the wind force.

The influence of wind force on the vehicle can be measured by driver's driving comfort degree. In the case of driving 
in wind, driver's driving comfort degree decreases with the increasing speed of wind. When the wind speed is small, drivers can not feel the impact of the wind. With the increase of wind speed, the driving comfort degree of the driver continues to reduce. When the degree reduced to a critical value, drivers need to adjust the driving state to reduce the impact caused by the wind and typically reduce the speed of vehicle. Thus, we define $\widetilde{v}=-\xi_{n} V\left(\Delta x_{n}\right) ; \xi_{n}$ is coefficient which varies with the change of driving comfort degree. Thus, the new car-following with the consideration of wind effect is as follows:

$$
\frac{d x_{n}^{2}(t)}{d t^{2}}=a\left[\left(1-\xi_{n}\right) V(\Delta x)-v_{n}\right]+\lambda \Delta v_{n} .
$$

Next, we define $\xi_{n}$ as follows:

$$
\xi_{n}= \begin{cases}0, & \text { if } \mu<\mu_{c}, \\ k_{1}+\frac{\left(1-k_{1}\right)\left(\mu-\mu_{c}\right)}{\left(k_{2}-1\right) \mu_{c}}, & \text { if } \mu_{c}<\mu<k_{2} \mu_{c}, \\ 1, & \text { if } \mu>k_{2} \mu_{c},\end{cases}
$$

where $\mu$ is sideway force coefficient which can measure the degree of driving comfort and the driving stability. $\mu_{c}$ is the critical value of sideway force coefficient when the driver feels uncomfortable, and $0<k_{1}<1, k_{2}>1$ are coefficients. When the sideway force coefficient is smaller than $\mu_{c}$, the driver does not need to consider the effect of the wind and just needs to pay attention to the driving state of the vehicle ahead. As the wind speed increases, the value of sideway force coefficient ( $\mu$ ) gradually increases. When the value of $\mu$ is bigger than $\mu_{c}$, the driver will feel uncomfortable to control the vehicle, so he needs to slow down to reduce uncomfortable feeling caused by the wind. If the sideway force coefficient reaches $k_{2} \mu_{c}$, the vehicle will reach the maximum deceleration to avoid the accident.

Equation of sideway force coefficient is expressed as

$$
\mu=\frac{v_{n}^{2}}{127 r}-i_{h}+\frac{F_{Y}}{G},
$$

where $v_{n}, r, i_{h}, G$, and $F_{Y}$ are vehicle speed, horizontal radius, super elevation, vehicle weight, and side force of wind, respectively. In the case of driving in the plane curve road section, we can set $i_{h}=0$. Taking the influence of the lift force of the wind into account, the vehicle weight $(G)$ can be rewritten as

$$
\bar{G}=G-F_{Z}
$$

Thus, (9) can be rewritten as

$$
\mu=\frac{v_{n}^{2}}{127 r}+\frac{F_{Y}}{G-F_{Z}} .
$$

Because (7) has taken the lift force and side force of the wind into account, it can be used to describe the driving behavior under varying speeds of wind.

\section{The Linear Stability Analysis}

Strong wind has great effect on traffic flow. However, little effort has been made to study the effects of strong wind on traffic flow from perspective of the linear stability analysis. In this section, the linear stability theory is applied to derive linear stability condition of the new proposed model in this section. The uniform traffic flow is defined by such a state that all vehicles move with the optimal velocity $\overline{V(\Delta x)}$ and the identical headway $h$.

Assuming $x_{n}(t)=x_{n}^{(0)}(t)+y_{n}(t)$, where $x_{n}^{(0)}(t)=h n+$ $V(h) t$ and $y_{n}(t)$ is a small deviation from the steady state $x_{n}^{(0)}(t)$, then we can rewrite (7) as

$$
\begin{aligned}
\frac{d^{2} y_{n}(t)}{d t^{2}}= & a\left[\left(1-\xi_{n}\right) V^{\prime}(h) \Delta y_{n}(t)-\frac{d y_{n}(t)}{d t}\right] \\
& +\lambda \frac{d \Delta y_{n}(t)}{d t}
\end{aligned}
$$

where $\Delta y_{n}(t)=y_{n+1}(t)-y_{n}(t)$. Expanding $y_{n}(t)$ in the Fourier-modes $y_{n}(t) \propto \exp (i k n+z t)$, we have

$$
\begin{aligned}
& z^{2}+z {[a-\lambda(\exp (i k)-1)] } \\
&-a\left(1-\xi_{n}\right) V^{\prime}(h)(\exp (i k)-1)=0 .
\end{aligned}
$$

Substituting $z=z_{1}(i k)+z_{2}(i k)^{2}+\cdots$ into (13), we can obtain the first- and second-order terms of coefficients in the expression of $z$, respectively:

$$
\begin{aligned}
& z_{1}=\left(1-\xi_{n}\right) V^{\prime}(h), \\
& z_{2}=\frac{z_{1}}{a}\left(\lambda+\frac{1}{2} a-z_{1}\right) .
\end{aligned}
$$

For small perturbations with long waves, the uniform steady state will become unstable when $z_{2}$ is negative. Thus the neutral stability curve is given by

$$
a_{s}=2\left[\left(1-\xi_{n}\right) V^{\prime}(h)-\lambda\right] \text {. }
$$

The uniform traffic flow will be stable if

$$
a_{s}>2\left[\left(1-\xi_{n}\right) V^{\prime}(h)-\lambda\right] \text {. }
$$

Figure 1 shows the neutral stability line in the headwaysensitivity space $(\Delta x, a)$ with different sets of $\xi_{n}$. For the case of $\xi_{n}=0$, the neutral stability line is the same as that of FVDM. The traffic flow is stable above the neutral stability line, while below the line traffic flow is unstable. The regime where the values of the headway give positive values of the stability function (see (15)) represents the unstable regime. The apex of each neutral stability curve represents the critical point $\left(h_{c}, a_{c}\right)$, where $h_{c}$ and $a_{c}$ are, respectively, the safety distance and the critical sensitivity. It can be seen clearly from Figure 1 that, given the same values of headway, the critical point and the neutral stability curve obtained from our model are significantly lower than those of FVDM. The new model has a smaller unstable regime, which means the stability of 


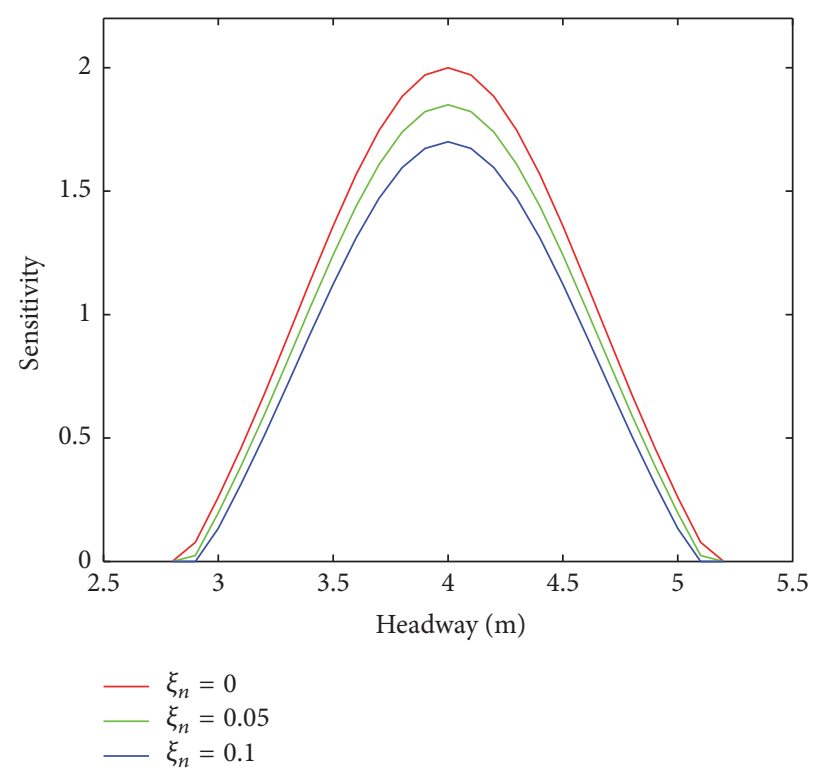

FIgURE 1: The neutral stability line in the headway-sensitivity space.

the traffic flow is improved as the value of $\xi_{n}$ increases. The result of Figure 1 indicates that since FVDM did not consider the effect of strong wind, the vehicle velocity calculated by FVDM is still high even when the wind speed gets higher, which will decrease the stability of traffic flow. On the other hand, we believe that the strong wind will reduce the vehicle's velocity; as a result, stability of traffic flow will be improved.

\section{Numerical Simulations}

In this section, we explore the impacts of the strong wind on driving behavior by using numerical method. Simulation is made to investigate evolution of small perturbation, lateral stability of vehicle, and vehicle's fuel consumption, respectively.

4.1. Evolution of a Small Perturbation. We study spatial-time evolution of small perturbation with the effect of wind in this subsection. To compare with the FVDM which has not considered the impact of wind, we suppose that there are $N$ vehicles running on a ring road whose length is $L=1000 \mathrm{~m}$ and those vehicles have same characters as $L c=5, B=2$, $H=1.5, G=9800$. The initial state is set as

$$
\begin{aligned}
& \Delta x_{n}(0)=\Delta x_{0} \quad \text { for } n=1,2, \ldots, N, \\
& \Delta x_{n}(1)=\Delta x_{0} \quad \text { for } n \neq 1, N, \\
& \Delta x_{n}(1)=\Delta x_{0}-1 \quad \text { for } n=1, \\
& \Delta x_{n}(1)=\Delta x_{0}+1 \quad \text { for } n=N .
\end{aligned}
$$

The total number of vehicles is $N=60, \Delta x_{0}=$ $L / N-L c$, and a periodic boundary condition is adopted in the simulation. Wind direction is always perpendicular to the direction of the vehicle, for simplicity. Other input parameters are set as follows:

$$
\begin{aligned}
a & =0.41, \\
\lambda & =0.5, \\
k_{1} & =0.02, \\
k_{2} & =2, \\
\mu_{c} & =0.2, \\
\rho & =1.293 \mathrm{~kg} / \mathrm{m}^{3}, \\
C_{Z} & =0.629, \\
C_{L} & =0.106 .
\end{aligned}
$$

Figure 2 shows the space-time evolution of the velocity after 500 seconds and the velocity profile of the 30th vehicle for different wind speed. From Figure 2, we can observe the following:

(1) Using our model with the consideration of wind effect, the maximum speed in Figure 2(b) is approximately $12 \mathrm{~m} / \mathrm{s}$ with wind speed at $20 \mathrm{~m} / \mathrm{s}$, which is significantly lower than that obtained by FVDM about $14 \mathrm{~m} / \mathrm{s}$ in Figure 2(a) because FVDM did not consider the wind effect. Moreover, maximum speed is lower than $10 \mathrm{~m} / \mathrm{s}$ with wind speed at $24 \mathrm{~m} / \mathrm{s}$ in Figure 2(c). These indicate that strong wind could significantly inhibit driving speed; the higher the wind speed, the lower the vehicle speed. The result is consistent with the phenomenon observed in real traffic that driver will slow down when the wind force is powerful.

(2) Figures 2(b) and 2(c) are simulation results under our model and from them we can see that the oscillation 

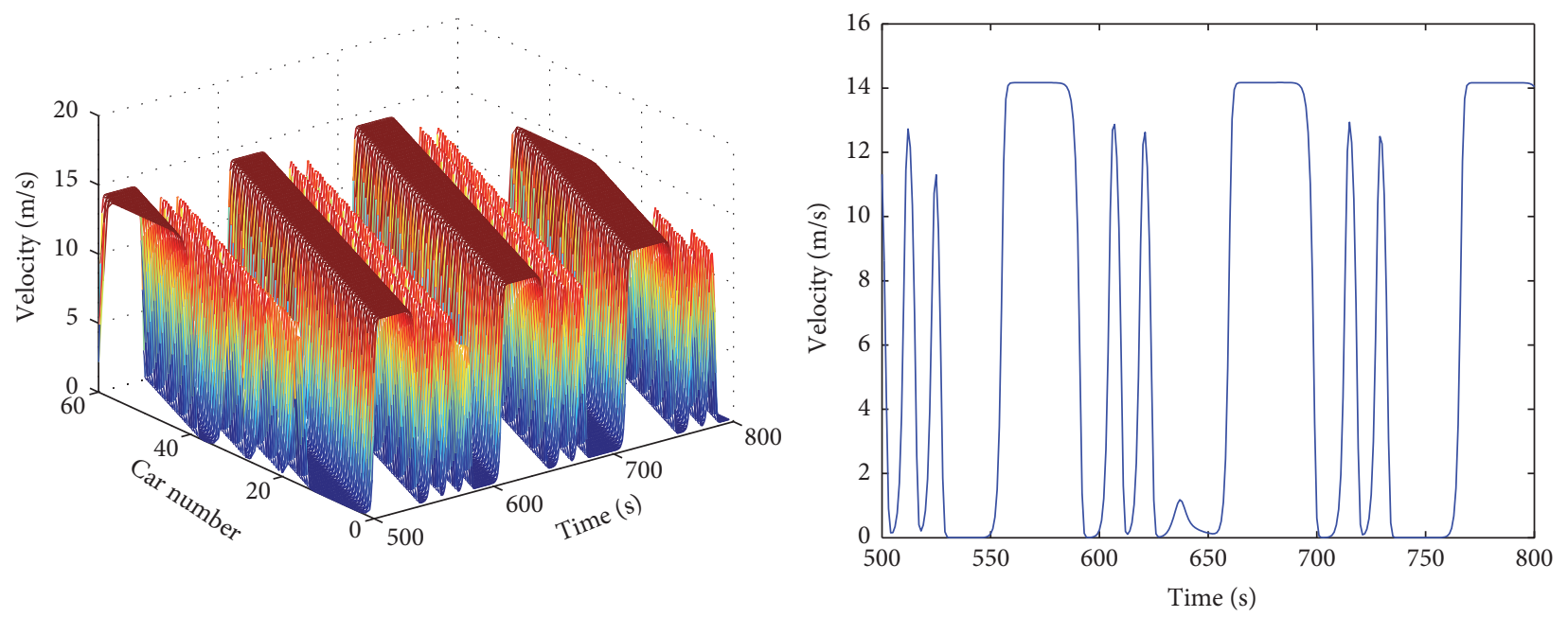

(a) FVDM
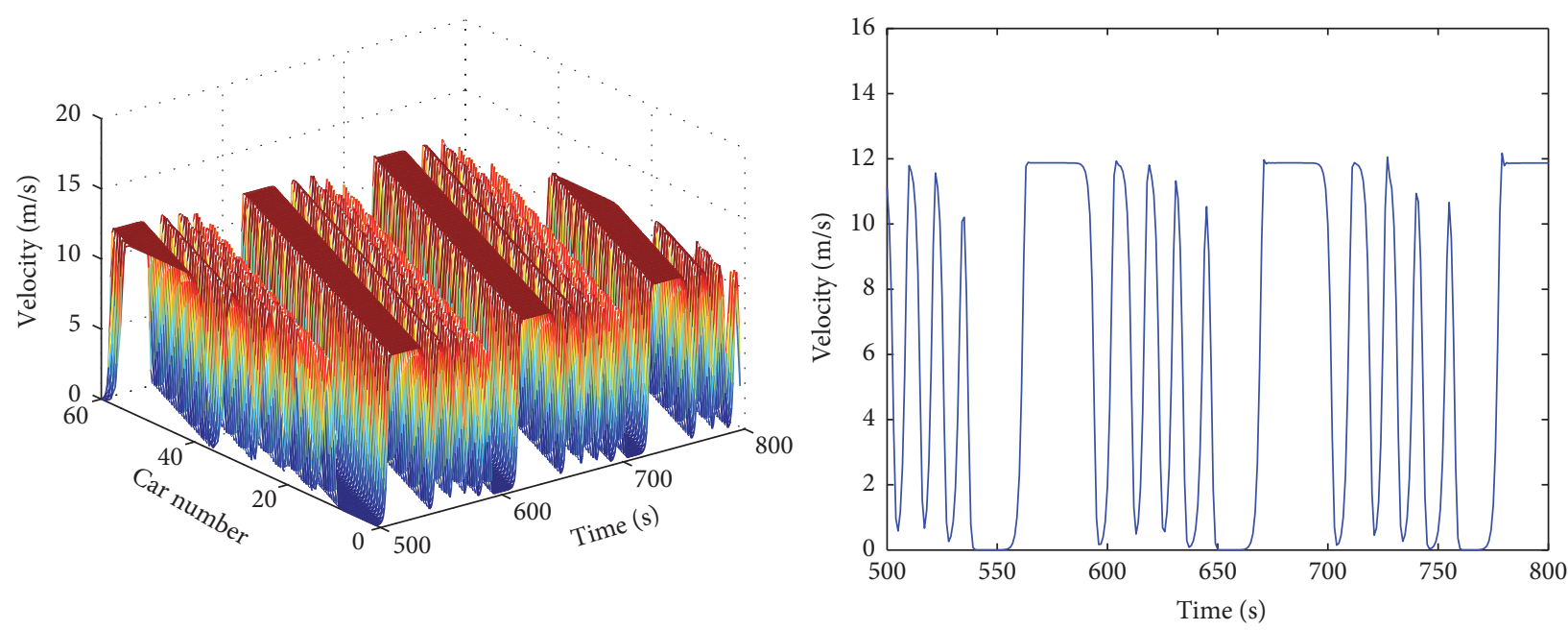

(b) Our model with wind speed at $20 \mathrm{~m} / \mathrm{s}$
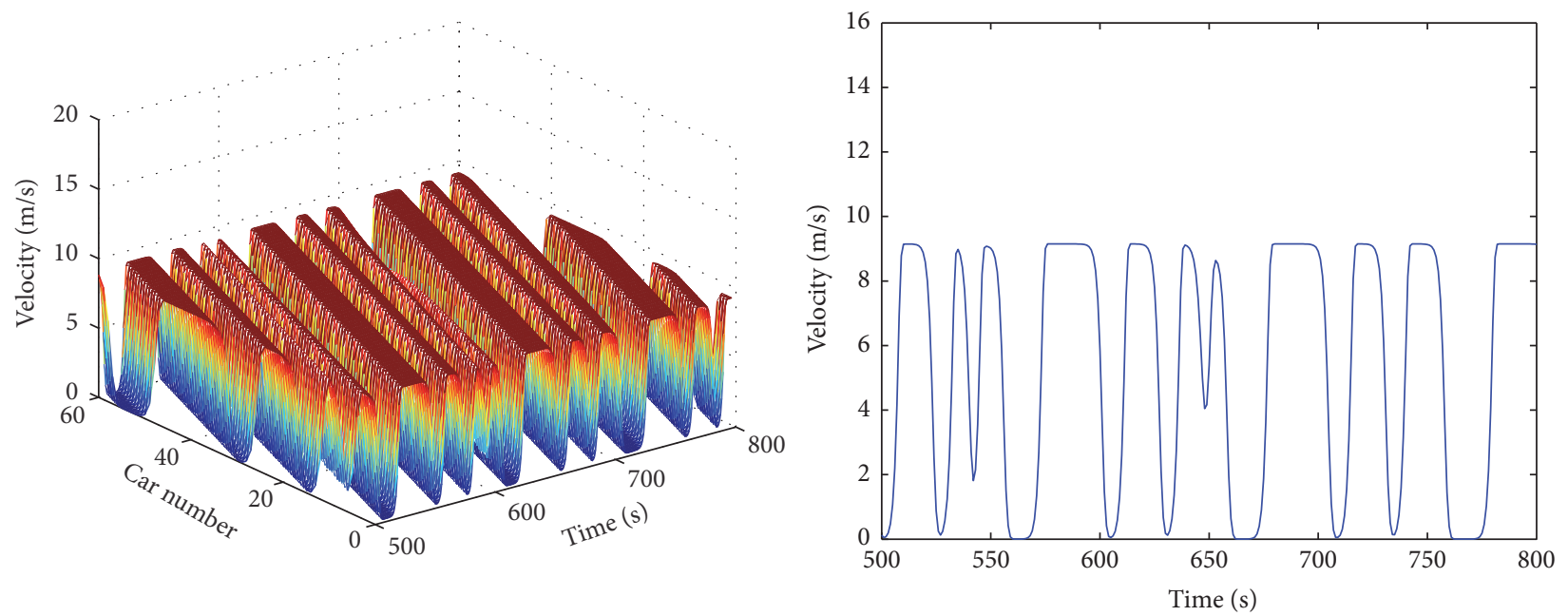

(c) Our model with wind speed at $24 \mathrm{~m} / \mathrm{s}$

FIGURE 2: Space-time evolution of the velocity and the velocity profile of the 30th vehicle for different wind speed from 500 seconds to 800 seconds, where (a) shows the results obtained by FVDM and (b) and (c) are the results of our model with wind speed at $20 \mathrm{~m} / \mathrm{s}$ and $24 \mathrm{~m} / \mathrm{s}$, respectively. 


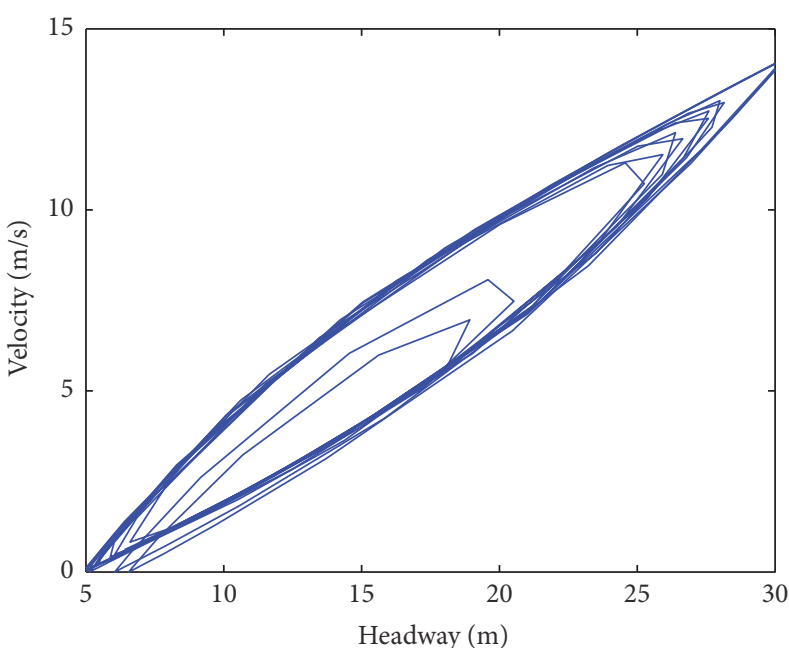

(a) FVDM

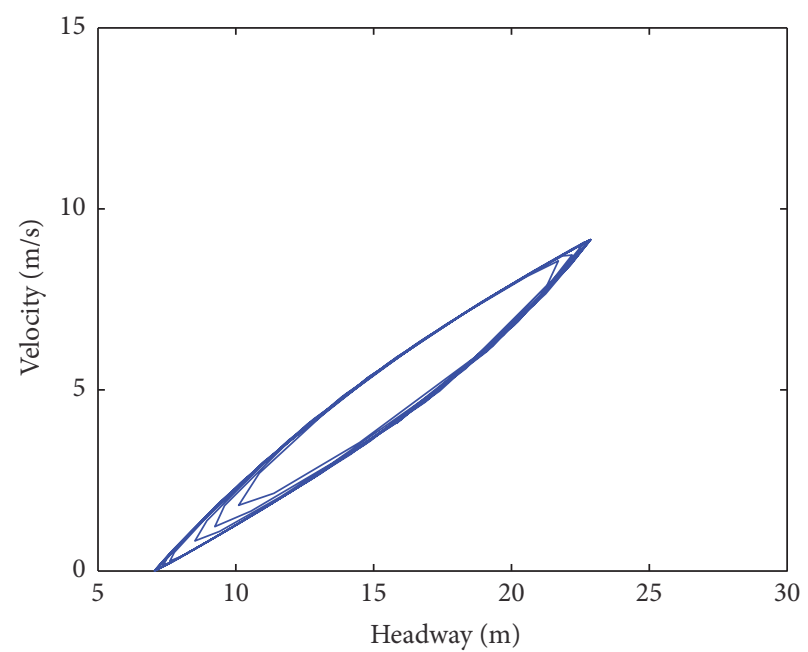

(b) Our model

FIgURE 3: Hysteresis loops for FVDM and our model.

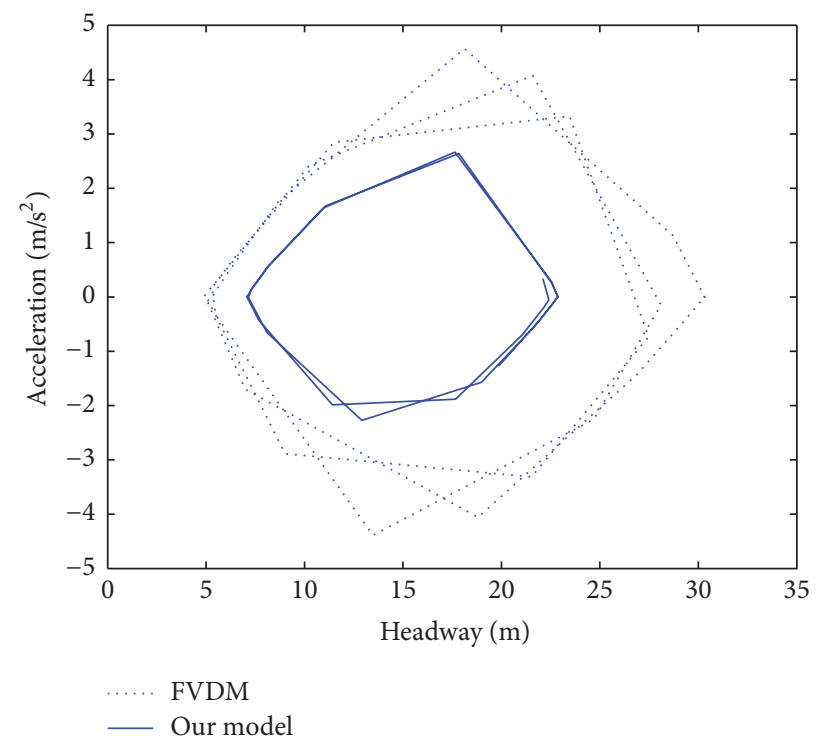

FIGURE 4: Vehicles' acceleration versus headway for FVDM and our model.

in Figure 2(c) is more gentle than those in Figure 2(b). It shows that drivers will be more careful to keep driving and try to stabilize the vehicle velocity when the wind speed gets higher.

(3) Stop-and-go traffic appears in Figure 2. The jam in Figure 2(a) is the most serious, followed by those in Figures 2(b) and 2(c). It explores that stop-andgo phenomenon is weakened since vehicle's velocity reduces with the increase of the wind speed.

We also use the hysteresis loops to demonstrate the relationship between velocity and space headway and the relationship between acceleration and space headway. Figure 3 exhibits the hysteresis loops after a sufficiently large time, where (a) and (b) are obtained from FVDM and our model. The 30th vehicle is selected as the target vehicle. Figure 4 represents the relationship between acceleration and space headway at time $600 \mathrm{~s}$, where the dotted line and solid line are obtained from FVDM and our model. Hysteresis loop having a larger size means that the stability of traffic flow is lower, and the stability of traffic flow is improved with the decrease of the size of the loop. From Figures 3 and 4, we can find that the hysteresis loop obtained from our model is much smaller than that from the FVDM. The result indicates that, by taking the effect of strong wind into account, the stability of the traffic flow simulated by our model is superior to that simulated by FVDM, which is consistent with the conclusion of Figure 1.

4.2. Lateral Stability of Vehicle. In this subsection, we investigate the influence of strong wind on the lateral stability of vehicle. Lateral stability refers to the vehicle's performance of resisting lateral overturn and side slip. Researches show that, 


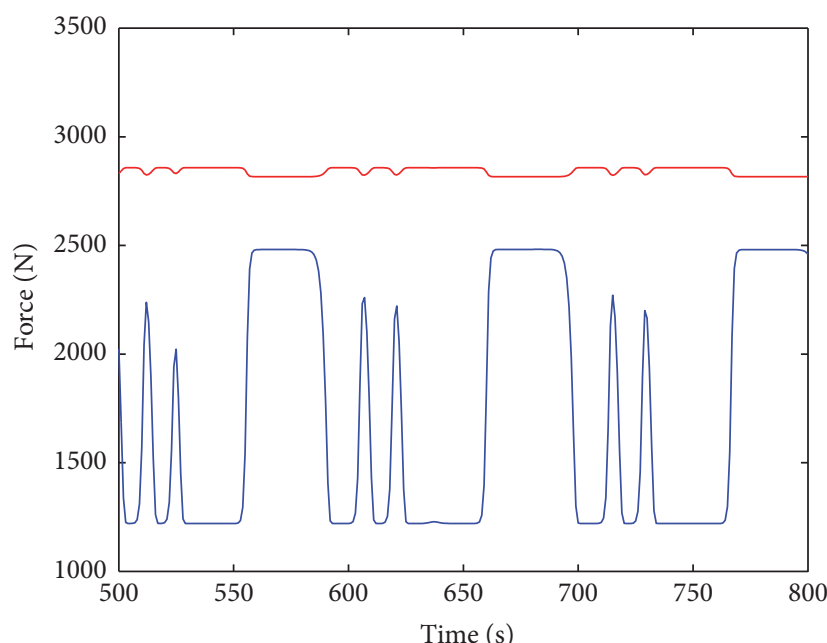

- Side friction

— Lateral force

(a) FVDM with wind speed at $20 \mathrm{~m} / \mathrm{s}$



- Side friction

— Lateral force

(c) Our model with wind speed at $20 \mathrm{~m} / \mathrm{s}$

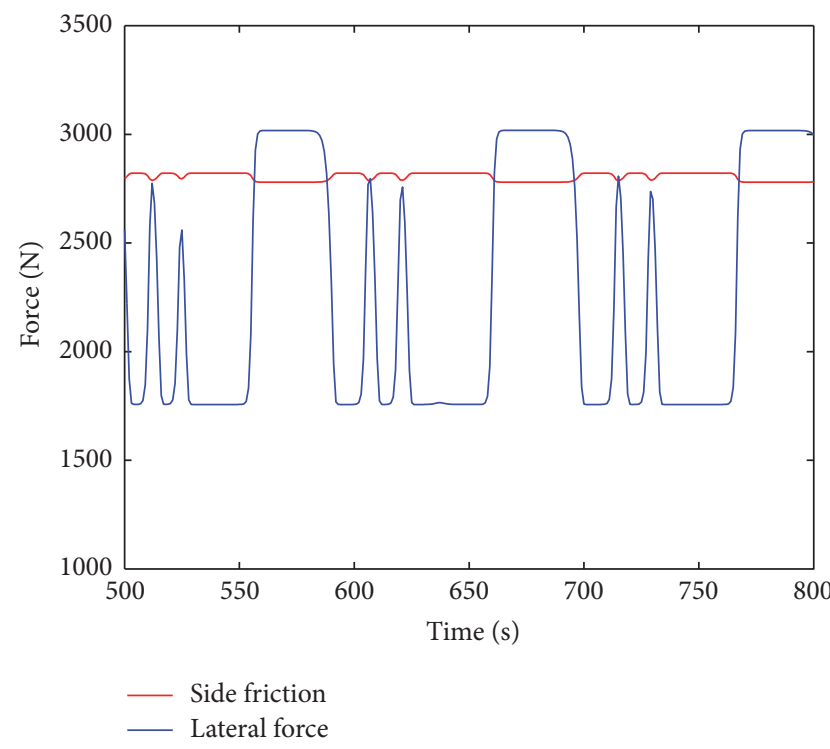

(b) FVDM with wind speed at $24 \mathrm{~m} / \mathrm{s}$

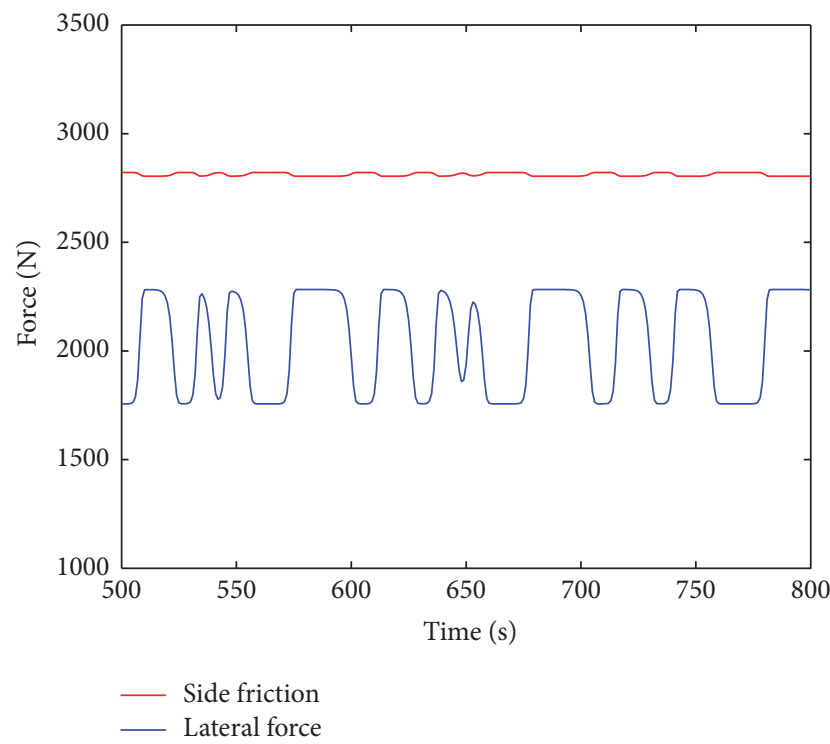

(d) Our model with wind speed at $24 \mathrm{~m} / \mathrm{s}$

FIGURE 5: The force profile of the 30th vehicle with different wind speed from 500 seconds to 800 seconds, where (a) and (b) are the results without consideration of wind effect and (c) and (d) are the results with consideration of wind effect.

under the identical road conditions and driving speed, side slip occurs before overturn with the enhancement of cross wind [50]. In real traffic, vehicle side slip will occur when the lateral force is greater than the side friction between the vehicle and the road surface. In view of this, lateral stability of the driving vehicle will be ensured as long as side slip is prevented.

Maximum side friction can be expressed as

$$
f_{s}=\zeta f
$$

where $f=\phi G$ is the maximum static friction force between vehicle and road. The permanents $\phi$ and $\zeta$ are, respectively, friction coefficient and sideway adhesion coefficient. In this paper $\phi, \zeta$ are, respectively, set as 0.5 and 0.6 .
In the case of driving on a ring road in the weather of strong winds, lateral force on vehicle is the resultant force of centrifugal force and wind force. When the wind force has same direction with the centrifugal force, lateral force will be a large increase with the increase of wind speed and possibly exceed the maximum side friction. Therefore, it is necessary to analyze the lateral force on vehicle in this situation.

Figure 5 shows the force evolution of the 30th vehicle for different wind speed after 500 seconds, where (a) and (b) are the results by FVDM with wind speed at $20 \mathrm{~m} / \mathrm{s}$ and $24 \mathrm{~m} / \mathrm{s}$, respectively. Figures $5(\mathrm{c})$ and $5(\mathrm{~d})$ are the results of our model with wind speed at $20 \mathrm{~m} / \mathrm{s}$ and $24 \mathrm{~m} / \mathrm{s}$, respectively. The red curve is the curve of maximum side friction and the blue curve is the curve of lateral force on the vehicle. The 
TABLE 1: The regression coefficients in (20).

\begin{tabular}{|c|c|c|c|c|}
\hline \multirow{2}{*}{$K_{i, j}^{e}$} & \multicolumn{4}{|c|}{$j$} \\
\hline & 0 & 1 & 2 & 3 \\
\hline \multicolumn{5}{|l|}{$i$} \\
\hline 0 & -0.679439 & 0.135273 & 0.015946 & -0.001189 \\
\hline 1 & 0.29665 & 0.004808 & -0.000020535 & $5.5409285 E-8$ \\
\hline 2 & -0.000276 & 0.000083329 & 0.000000937 & $-2.479644 E-8$ \\
\hline 3 & 0.000001487 & -0.000061321 & 0.000000304 & $-4.467234 E-9$ \\
\hline
\end{tabular}

initial conditions are set as (17). Comparing with the FVDM, we can draw the conclusions from Figure 5: (1) The lateral force increases with wind speed. Figures 5(a) and 5(b) are the results obtained by FVDM with different speed of wind. As the wind speed increases from $20 \mathrm{~m} / \mathrm{s}$ in Figure 5(a) to $24 \mathrm{~m} / \mathrm{s}$ in Figure 5(b), the maximum lateral force on the vehicle corresponding increases from about $2500 \mathrm{~N}$ to $3000 \mathrm{~N}$. The curve of lateral force surpasses the curve of maximum side friction three times in Figure 5(b), so sideslip occurs three times. On the contrary, by using our model, the curve of lateral force is always significantly lower than the curve of maximum side friction in Figures 5(c) and 5(d), so the sideslip has not occurred. It is well known that vehicles should slow down to avoid the sideslip when the crosswind becomes powerful. Thus, the numerical results show that our model can better reproduce the real traffic phenomena with the effect of strong wind.

(2) The amplitude and the frequency of lateral force curve in Figure 5(d) are, respectively, smaller than those in Figure 5(c). It indicates that the increase of wind force plays a role in prompting driver to be more careful while driving and thereby leads to a more gentle curve of the lateral force.

4.3. Vehicle's Fuel Consumption. We explore the effect of strong wind on vehicle's fuel consumption because the existing studies show that fuel consumption can be affected by driving behavior [51-53]. Ahn [51] proposed a VT-micro model to formulate the vehicle's fuel consumption in 1998. The VT-micro model can be written as

$$
\begin{aligned}
\ln (\mathrm{MOEe}) & =\sum_{i=0}^{3} \sum_{j=0}^{3}\left(K_{i, j}^{e} \times v^{i} \times\left(\frac{d v}{d t}\right)^{j}\right), \\
\mathrm{MOEe} & =\exp \left(\sum_{i=0}^{3} \sum_{j=0}^{3}\left(K_{i, j}^{e} \times v^{i} \times\left(\frac{d v}{d t}\right)^{j}\right)\right),
\end{aligned}
$$

where MOEe is the vehicle's fuel consumption rate and its unit is $\mathrm{ml} / \mathrm{s} ; K_{i, j}^{e}$ is the regression coefficient (see Table 1 ).

To display the difference of the vehicle's fuel consumption under different wind speed, we calculate the evolution of the fuel consumption rate from 500 seconds to 800 seconds and the profile of the $30 t h$ vehicle under different wind speed. The initial conditions are set as (17).

Figure 6 shows the evolution of the fuel consumption rate and the profile of the 30th vehicle for different wind speed from 500 seconds to 800 seconds, where (a) shows the results obtained by FVDM; (b) and (c) are the results by our model with wind speed at $20 \mathrm{~m} / \mathrm{s}$ and $24 \mathrm{~m} / \mathrm{s}$, respectively. From Figure 6 , we can see that without the consideration of the wind effect, the amplitude of fuel consumption rate simulated by FVDM in Figure 6(a) is higher than that simulated by our model in Figures 6(b) and 6(c). Furthermore, the amplitude of fuel consumption rate is lower in Figure 6(c) when the wind speed is $24 \mathrm{~m} / \mathrm{s}$ than that in Figure 6(b) when the wind speed is $20 \mathrm{~m} / \mathrm{s}$. It shows that the fuel consumption is affected by the wind. As the wind speed increases, the amplitude of fuel consumption rate decreases gradually.

Though we obtain the conclusion from Figure 6 that the wind can affect the amplitude of fuel consumption rate, we can not determine whether the effect of strong wind will reduce vehicle's fuel consumption. In order to further study the effect of strong wind on vehicle's fuel consumption, we simulated each vehicle's total fuel consumption for a period of time by using FVDM and our model, respectively. Figure 7 exhibits each vehicle's total fuel consumption for $1000 \mathrm{~s}$ with different wind speed, where (a) and (b) are, respectively, with wind speed at $20 \mathrm{~m} / \mathrm{s}$ and $24 \mathrm{~m} / \mathrm{s}$. As can be seen from Figure 7, the curves of each vehicle's total fuel consumption simulated by our model are lower than the curve simulated by FVDM. Also, each vehicle's total fuel consumption with wind speed at $24 \mathrm{~m} / \mathrm{s}$ is lower than that with $20 \mathrm{~m} / \mathrm{s}$. Simulation results indicate that by taking the effect of strong wind into account the driver will reduce the vehicle's velocity to avoid the traffic accident, so it leads to the reduction of fuel consumption. Therefore, the simulation results are consistent with the conclusions of Figure 6.

\section{Conclusions}

In this paper, we present an extended car-following model with the consideration of the wind effect based on the FVD model. Linear stability analysis is carried out to study the traffic characteristics by making use of linear stability analysis. Numerical analysis is made to explore the effect of strong wind on evolution of a small perturbation, lateral stability of vehicle, and vehicle's fuel consumption. The simulation result shows that the developed model can qualitatively reproduce the impact of the strong wind on traffic flow, which means the new developed model is reasonable. Nevertheless, there are still some limitations in this paper. For example, we do not consider the influence caused by wind changing direction, and, moreover, strong wind often causes low visibility, but it is not currently taken into account. 

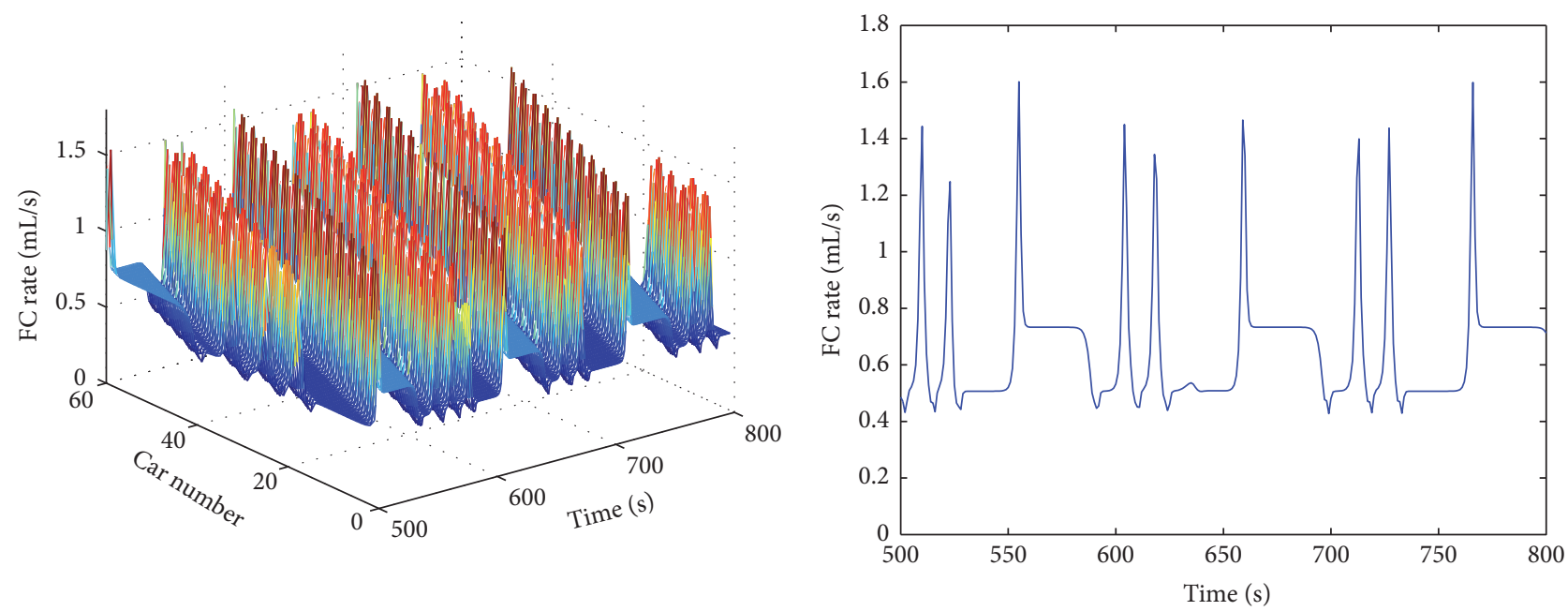

(a) FVDM
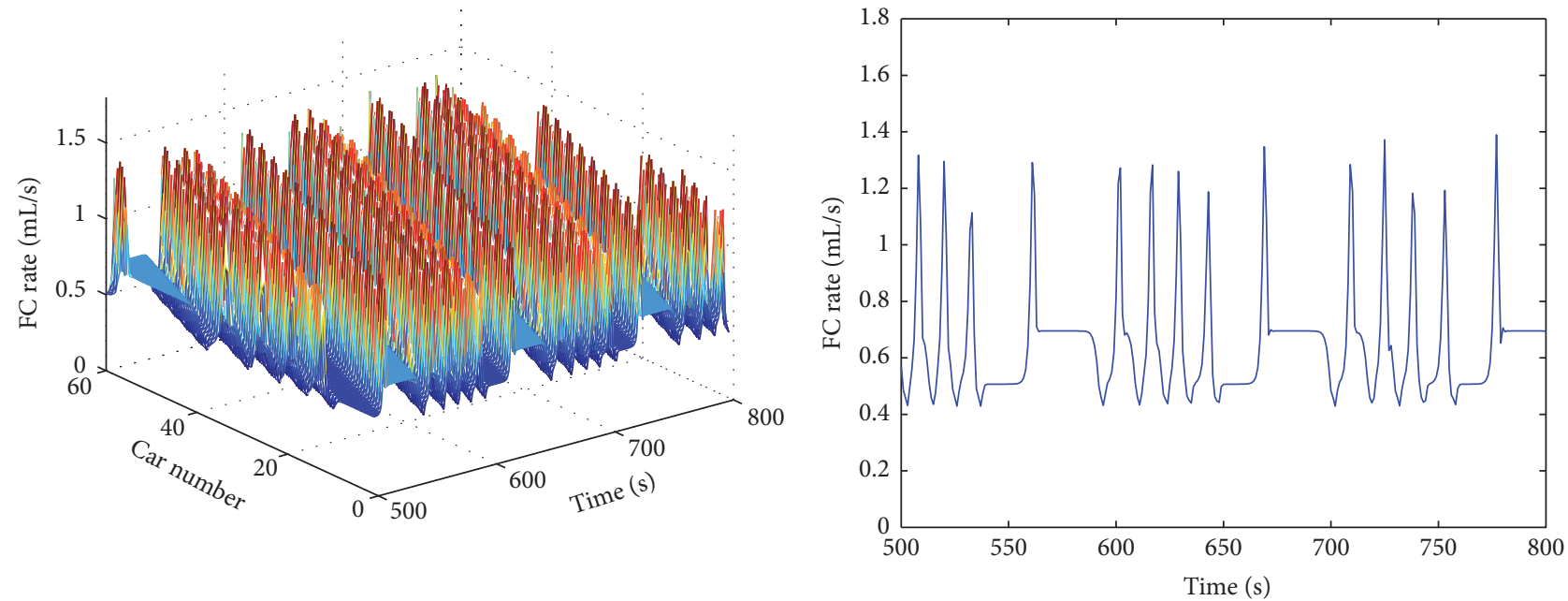

(b) Our model with wind speed at $20 \mathrm{~m} / \mathrm{s}$


(c) Our model with wind speed at $24 \mathrm{~m} / \mathrm{s}$

FIgURE 6: Evolution of the fuel consumption rate and the profile of the single vehicle. 


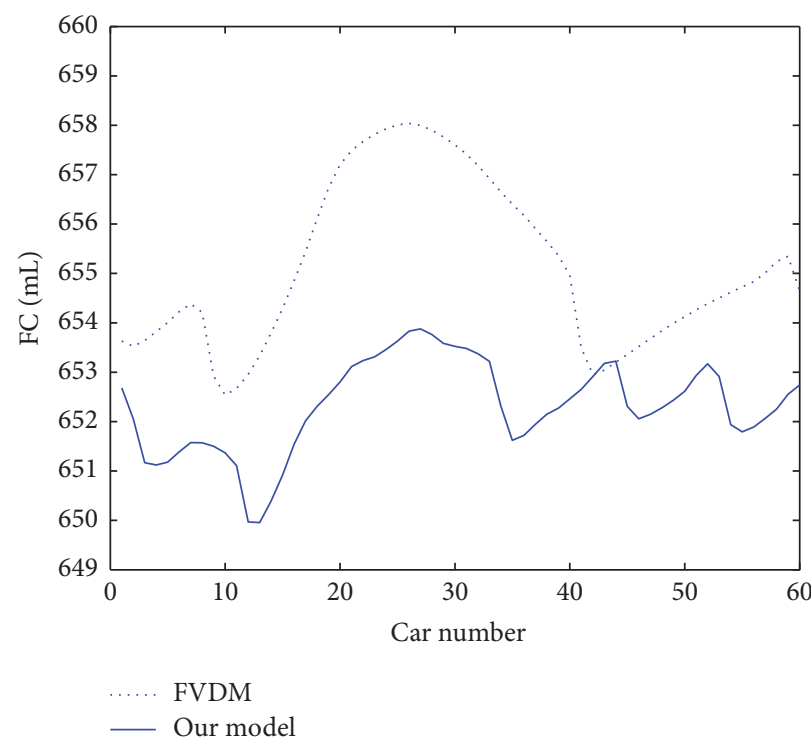

(a) Wind speed at $20 \mathrm{~m} / \mathrm{s}$

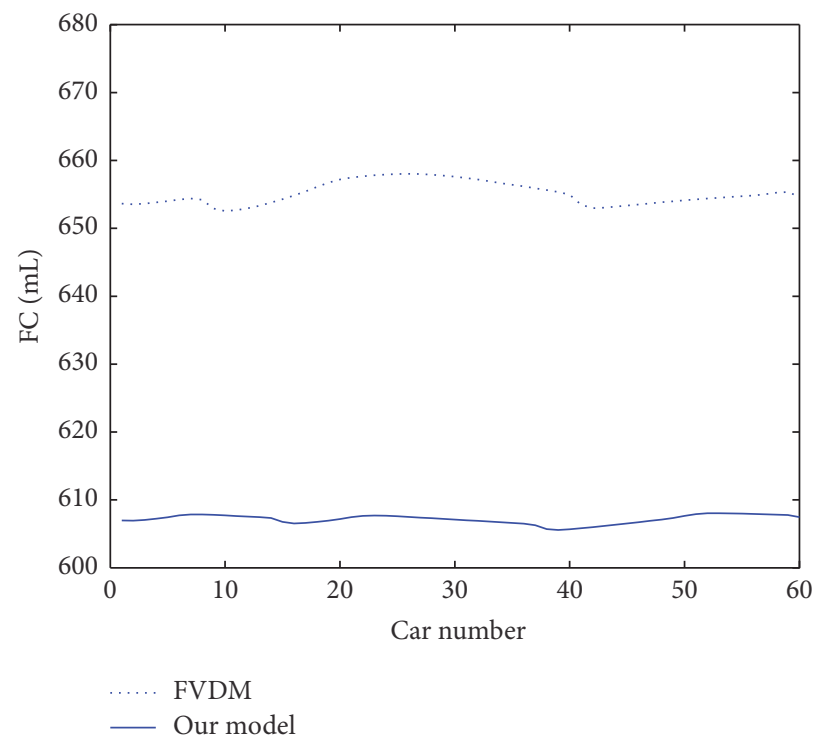

(b) Wind speed at $24 \mathrm{~m} / \mathrm{s}$

FIGURE 7: Each vehicle's total fuel consumption for a period of time.

In the further study, we will develop a new car-following model on the basis of the model presented in this paper to address the above limitations. Theoretical analysis and experimental study will be carried out to explore the effect of wind changing direction and low visibility on traffic flow.

\section{Conflicts of Interest}

The authors declare that there are no conflicts of interest regarding the publication of this paper.

\section{Acknowledgments}

This work is partially supported by the National Nature Science Foundation of China (Grant no. 61134004), Gansu Province Educational Research Project (Grant no. 2015B130), and the Fundamental Research Funds for the Central Universities (no. 31920160045).

\section{References}

[1] L. A. Pipes, "An operational analysis of traffic dynamics," Journal of Applied Physics, vol. 24, no. 3, pp. 274-281, 1953.

[2] G. F. Newell, "Nonlinear effects in the dynamics of car following," Operations Research, vol. 9, pp. 209-229, 1961.

[3] M. Bando, K. Hasebe, A. Nakayama, A. Shibata, and Y. Sugiyama, "Dynamical model of traffic congestion and numerical simulation," Physical Review E: Statistical, Nonlinear, and Soft Matter Physics, vol. 51, no. 2, pp. 1035-1042, 1995.

[4] D. Helbing and B. Tilch, "Generalized force model of traffic dynamics," Physical Review E: Statistical, Nonlinear, and Soft Matter Physics, vol. 58, no. 1, pp. 133-138, 1998.

[5] R. Jiang, Q. Wu, and Z. Zhu, "Full velocity difference model for a car-following theory," Physical Review E: Statistical, Nonlinear, and Soft Matter Physics, vol. 64, article 017101, no. 1, Article ID 017101, 2001.
[6] L. C. Davis, "Modifications of the optimal velocity traffic model to include delay due to driver reaction time," Physica A: Statistical Mechanics and its Applications, vol. 319, pp. 557-567, 2003.

[7] R. Sipahi, F. M. Atay, and S.-I. Niculescu, "Stability of traffic flow behavior with distributed delays modeling the memory effects of the drivers," SIAM Journal on Applied Mathematics, vol. 68, no. 3, pp. 738-759, 2007/08.

[8] Y. Jin and M. Xu, "Stability analysis in a car-following model with reaction-time delay and delayed feedback control," Physica A: Statistical Mechanics and its Applications, vol. 459, pp. 107116, 2016.

[9] D. Ngoduy, "Linear stability of a generalized multi-anticipative car following model with time delays," Communications in Nonlinear Science and Numerical Simulation, vol. 22, no. 1-3, pp. 420-426, 2015.

[10] C. Wagner, "Asymptotic solutions for a multi-anticipative carfollowing model," Physica A: Statistical Mechanics and its Applications, vol. 260, no. 1-2, pp. 218-224, 1998.

[11] K. Hasebe, A. Nakayama, and Y. Sugiyama, "Equivalence of linear response among extended optimal velocity models," Physical Review E: Statistical, Nonlinear, and Soft Matter Physics, vol. 69, article 017103, no. 1, 2004.

[12] T. Nagatani, "Stabilization and enhancement of traffic flow by the next-nearest-neighbor interaction," Physical Review E: Statistical Physics, Plasmas, Fluids, and Related Interdisciplinary Topics, vol. 60, pp. 6395-6401, 1999.

[13] H. X. Ge, S. Q. Dai, L. Y. Dong, and Y. Xue, "Stabilization effect of traffic flow in an extended car-following model based on an intelligent transportation system application," Physical Review E: Statistical, Nonlinear, and Soft Matter Physics, vol. 70, no. 6, Article ID 066134, 2004.

[14] T.-Q. Tang, H.-J. Huang, and Z.-Y. Gao, "Stability of the carfollowing model on two lanes," Physical Review E: Statistical, Nonlinear, and Soft Matter Physics, vol. 72, no. 6, Article ID 066124, 2005.

[15] G. Peng, "A new lattice model of two-lane traffic flow with the consideration of optimal current difference," Communications 
in Nonlinear Science and Numerical Simulation, vol. 18, no. 3, pp. 559-566, 2013.

[16] G. Peng, "A new lattice model of the traffic flow with the consideration of the driver anticipation effect in a two-lane system," Nonlinear Dynamics, vol. 73, no. 1-2, pp. 1035-1043, 2013.

[17] T. Wang, Z. Gao, J. Zhang, and X. Zhao, "A new lattice hydrodynamic model for two-lane traffic with the consideration of density difference effect," Nonlinear Dynamics, vol. 75, no. 1-2, pp. 27-34, 2014.

[18] Y. Jia, Y. Du, and J. Wu, "Stability Analysis of a Car-Following Model on Two Lanes," Mathematical Problems in Engineering, vol. 2014, Article ID 727560, 2014.

[19] H.-x. Ge, X.-p. Meng, H.-b. Zhu, and Z.-P. Li, "Feedback control for car following model based on two-lane traffic flow," Physica A: Statistical Mechanics and its Applications, vol. 408, pp. 28-39, 2014.

[20] K. Aghabayk, M. Sarvi, and W. Young, "Attribute selection for modelling driver's car-following behaviour in heterogeneous congested traffic conditions," Transportmetrica A: Transport Science, vol. 10, no. 5, pp. 457-468, 2014.

[21] D. Ngoduy, "Effect of the car-following combinations on the instability of heterogeneous traffic flow," Transportmetrica $B$, vol. 3, no. 1, pp. 44-58, 2015.

[22] T. Nagatani, "Complex motion of a shuttle bus between two terminals with periodic inflows," Physica A: Statistical Mechanics and its Applications, vol. 449, pp. 254-264, 2016.

[23] T. Nagatani, "Effect of stoppage time on motion of a bus through a sequence of signals," Physica A: Statistical Mechanics and its Applications, vol. 465, pp. 297-304, 2017.

[24] M. Treiber, A. Kesting, and D. Helbing, "Delays, inaccuracies and anticipation in microscopic traffic models," Physica A: Statistical Mechanics and its Applications, vol. 360, no. 1, pp. 7188, 2006.

[25] L.-J. Zheng, C. Tian, D.-H. Sun, and W.-N. Liu, "A new carfollowing model with consideration of anticipation driving behavior," Nonlinear Dynamics, vol. 70, no. 2, pp. 1205-1211, 2012.

[26] T. Q. Tang, C. Y. Li, and H. J. Huang, "A new car-following model with the consideration of the driver's forecast effect," Physics Letters A, vol. 374, no. 38, pp. 3951-3956, 2010.

[27] G.-h. Peng and R.-j. Cheng, "A new car-following model with the consideration of anticipation optimal velocity," Physica A: Statistical Mechanics and its Applications, vol. 392, no. 17, pp. 3563-3569, 2013.

[28] Y.-R. Kang, D.-H. Sun, and S.-H. Yang, "A new car-following model considering driver's individual anticipation behavior," Nonlinear Dynamics, vol. 82, no. 3, pp. 1293-1302, 2015.

[29] G. Peng, F. Nie, B. Cao, and C. Liu, “A driver's memory lattice model of traffic flow and its numerical simulation," Nonlinear Dynamics, vol. 67, no. 3, pp. 1811-1815, 2012.

[30] H.-X. Ge, F. Lv, P.-J. Zheng, and R.-J. Cheng, "The timedependent Ginzburg-Landau equation for car-following model considering anticipation-driving behavior," Nonlinear Dynamics, vol. 76, no. 2, pp. 1497-1501, 2014.

[31] D.-W. Liu, Z.-K. Shi, and W.-H. Ai, "Enhanced stability of car-following model upon incorporation of short-term driving memory," Communications in Nonlinear Science and Numerical Simulation, vol. 47, pp. 139-150, 2017.

[32] G. Peng, W. Lu, H. He, and Z. Gu, "Nonlinear analysis of a new car-following model accounting for the optimal velocity changes with memory," Communications in Nonlinear Science and Numerical Simulation, vol. 40, pp. 197-205, 2016.
[33] S. Yu and Z. Shi, "Dynamics of connected cruise control systems considering velocity changes with memory feedback," Measurement, vol. 64, pp. 34-48, 2015.

[34] T.-Q. Tang, K.-W. Xu, S.-C. Yang, and H.-Y. Shang, "Influences of battery exchange on the vehicle's driving behavior and running time under car-following model," Measurement, vol. 59, pp. 30-37, 2015.

[35] D. Yang, P. Jin, Y. Pu, and B. Ran, "Safe distance car-following model including backward-looking and its stability analysis," The European Physical Journal B, vol. 86, no. 3, Art. 92, 11 pages, 2013.

[36] W.-X. Zhu, D. Jun, and L.-D. Zhang, "A compound compensation method for car-following model," Communications in Nonlinear Science and Numerical Simulation, vol. 39, pp. 427441, 2016.

[37] T. Q. Tang, J. He, S. C. Yang, and H. Y. Shang, "A car-following model accounting for the driver's attribution," Physica A, vol. 419, pp. 293-300, 2015.

[38] T. Nagatani, "Effect of perception irregularity on chain-reaction crash in low visibility," Physica A: Statistical Mechanics and its Applications, vol. 427, pp. 92-99, 2015.

[39] T. Nagatani, "Traffic jam at adjustable tollgates controlled by line length," Physica A: Statistical Mechanics and its Applications, vol. 442, pp. 131-136, 2016.

[40] D.-H. Sun, G. Zhang, W.-N. Liu, M. Zhao, and S.-L. Cheng, "Analysis of anticipation driving effect in traffic lattice hydrodynamic model with on-ramp," Nonlinear Dynamics, vol. 81, no. 1-2, pp. 907-916, 2015.

[41] G. Peng, H. He, and W.-Z. Lu, "A new car-following model with the consideration of incorporating timid and aggressive driving behaviors," Physica A: Statistical Mechanics and its Applications, vol. 442, pp. 197-202, 2016.

[42] S. Yu and Z. Shi, "An extended car-following model considering vehicular gap fluctuation," Measurement, vol. 70, pp. 137-147, 2015.

[43] D. Sun, Y. Kang, and S. Yang, "A novel car following model considering average speed of preceding vehicles group," Physica A: Statistical Mechanics and its Applications, vol. 436, pp. 103109, 2015.

[44] S. Yu and Z. Shi, "An improved car-following model considering relative velocity fluctuation," Communications in Nonlinear Science and Numerical Simulation, vol. 36, pp. 319-326, 2016.

[45] S. D. Kwon, D. H. Kim, and S. H. Lee, "Design criteria of wind barriers for traffic. part 1: wind barrier performance," Wind and Structures, vol. 14, pp. 55-70, 2011.

[46] C. J. Baker, "A simplified analysis of various types of windinduced road vehicle accidents," Journal of Wind Engineering \& Industrial Aerodynamics, vol. 22, no. 1, pp. 69-85, 1986.

[47] C. J. Baker, "The quantification of accident risk for road vehicles in cross winds," Journal of Wind Engineering \& Industrial Aerodynamics, vol. 52, no. C, pp. 93-107, 1994.

[48] J. L. Xu, H. Wang, L. P. Zhao, and Y. J. Han, "Research on minimum radius of highway horizontal curve with crosswind considered," China Journal of Highway and Transport, vol. 27, no. 1, pp. 38-43, 2014.

[49] Z. Q. Gu, Automobile Aerodynamics, China Communications Press, Beijing, 2005.

[50] J. B. Pang, D. L. Wang, A. R. Chen, and Z. X. Lin, "Probability evaluating method of bridge deck side wind effects on driving safety," China Journal of Highway and Transport, vol. 19, pp. 5964, 2006. 
[51] K. Ahn, Microscopic fuel consumption and emission modeling [Ph.D. thesis], Civil and Environmental Engineering, Virginia Polytechnic Institute and State University, Blacksburg, Va, USA, 1998.

[52] T. Q. Tang, J. G. Li, S. C. Yang, and H. Y. Shang, "Effects of onramp on the fuel consumption of the vehicles on the main road under car-following model," Physica A, vol. 419, no. 15, pp. 293300, 2015.

[53] T.-Q. Tang, H.-J. Huang, and H.-Y. Shang, "Influences of the driver's bounded rationality on micro driving behavior, fuel consumption and emissions," Transportation Research Part D: Transport and Environment, vol. 41, pp. 423-432, 2015. 


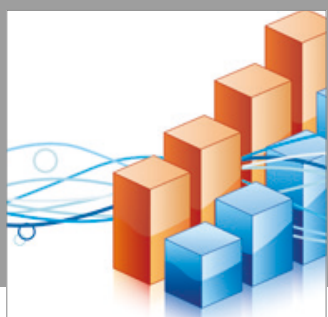

Advances in

Operations Research

vatersals

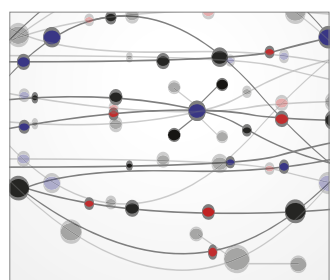

\section{The Scientific} World Journal
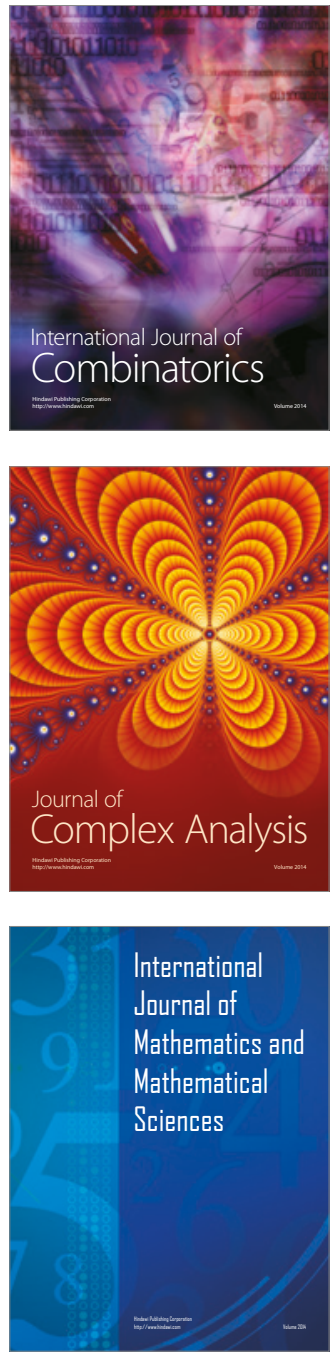
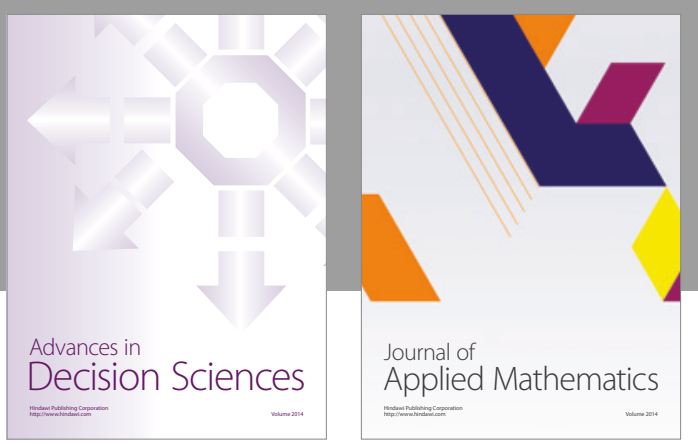

Algebra

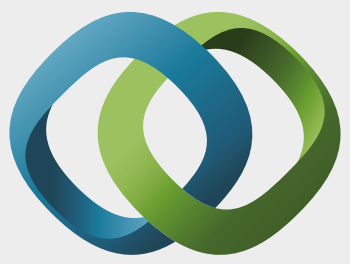

\section{Hindawi}

Submit your manuscripts at

https://www.hindawi.com
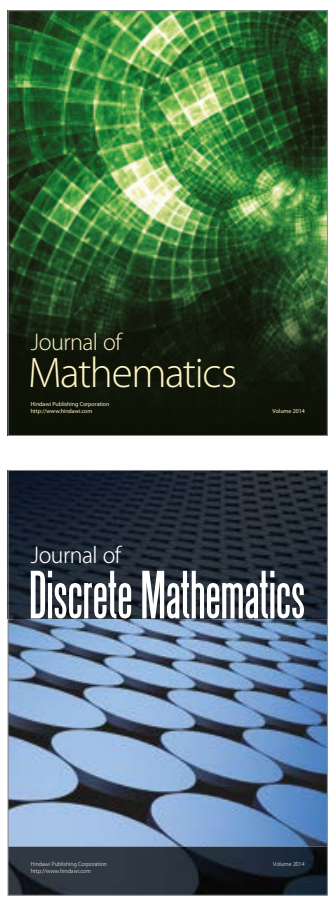

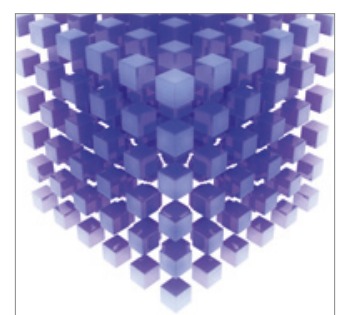

Mathematical Problems in Engineering
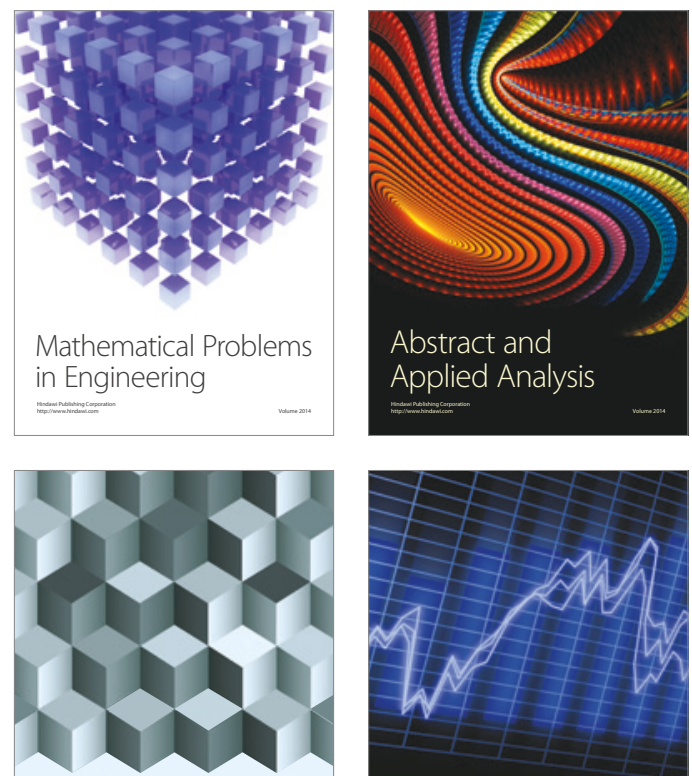

Journal of

Function Spaces

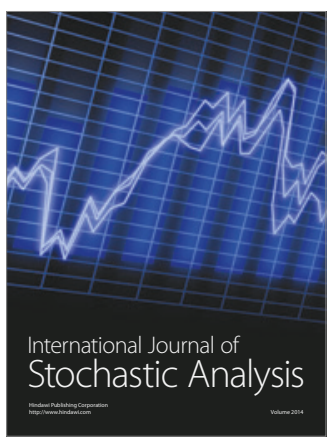

Probability and Statistics
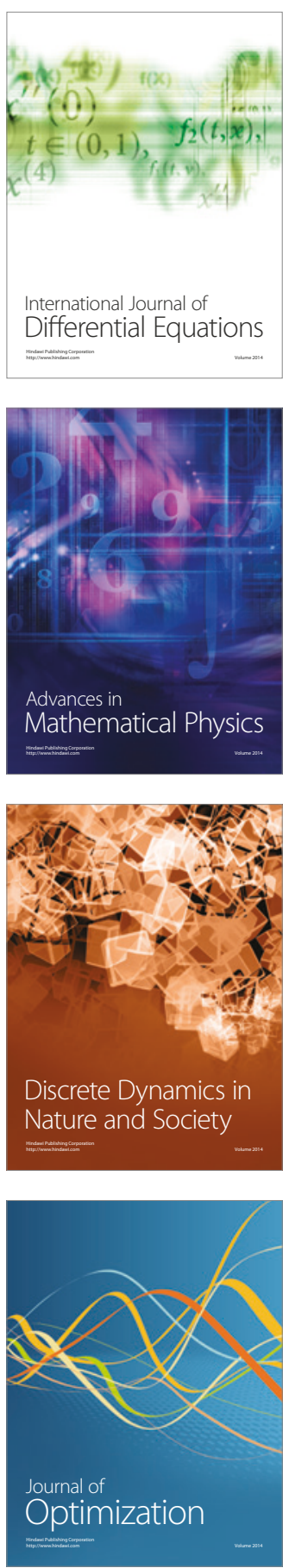